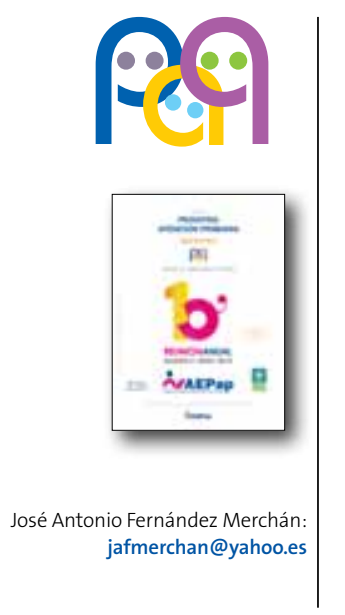

\title{
Foro profesional
}

\author{
¿Qué utilidad tiene la ecografía para el pediatra \\ de Atención Primaria?
}

\author{
J. A. Fernández Merchán \\ Pediatra. Área de Salud de Plasencia, Cáceres. España. \\ Grupo de Ecografía Clínica Pediátrica de la AEPap.
}

\section{INTRODUCCIÓN}

La ecografía nació en el medio hospitalario relacionada con la especialidad de Radiología, pero a estas alturas ya nadie duda de que sea una técnica diagnóstica asumida por determinadas especialidades en las que se ha convertido en un referente, como son la Obstetricia y Ginecología o la Cardiología. A día de hoy, otras muchas especialidades están sumando la ecografía a su arsenal diagnóstico: digestólogos, urólogos, anestesistas, intensivistas, internistas, reumatólogos, médicos deportivos, etc.

Desde hace unos años existe una corriente de interés por la ecografía en la Atención Primaria (AP) de Salud que se ha plasmado en multitud de cursos y propuestas de formación por parte de las principales sociedades científicas afines y la puesta en marcha de programas de implantación en varias comunidades autónomas como Galicia, Extremadura, Andalucía y Madrid. Son muchos los médicos de AP que ya utilizan la ecografía en su día a día ${ }^{1}$. Los pediatras de AP no debemos estar ajenos a esta tendencia y más cuando a priori se dan una serie de circunstancias que favorecen el uso de la ecografía en nuestras consultas, como son por ejemplo la inocuidad, evitando en ocasiones otras pruebas innecesarias a veces con radiaciones ionizantes, principio básico en la protección radiológica en Pediatría.

Dentro de esta corriente de interés por la ecografía nos planteamos, como pediatras de AP, si puede sernos útil, qué ventajas e inconvenientes tiene, en qué procesos nos puede servir y qué proceso formativo debería seguirse para aprender esta técnica de diagnóstico por imagen.

\section{¿QUUÉ ES LA ECOGRAFÍA?}

La ecografía es una técnica diagnóstica basada en el uso de ondas de ultrasonido (US), las cuales son emitidas a través de una sonda que hace las veces de emisor y receptor. Las ondas de US que vuelven a la sonda lo hacen después de haber pasado una serie de obstáculos (órganos y tejidos) con los que han interactuado, atravesándolos, atenuándose y rebotando antes o después. La unidad de procesamiento, a través de un software, se encarga de transformar esas ondas rebotadas o ecos en una imagen de escala de grises, que es la que finalmente vemos en una pantalla en tiempo real y que nos permite valorar las estructuras y órganos objeto de 
estudio no solo morfológicamente sino también en dinámico ${ }^{2}$.

Por tanto, el instrumento del que nos valemos, o ecógrafo, va a disponer, básicamente, de una o varias sondas, una unidad de procesamiento y una pantalla.

La ventaja de esta técnica aplicada a la Pediatría es que, en general, obtenemos mejores imágenes y de mayor resolución, porque los niños tienen una mayor proporción de agua que los adultos y un estrato graso mucho menor, lo que favorece la transmisión del US y en consecuencia la calidad y resolución de la imagen final.

El uso de la ecografía en AP se justifica porque, junto a la clínica y la exploración, aumenta la capacidad resolutiva, la fiabilidad y el rendimiento diagnóstico, reorienta la actitud terapéutica y ahorra recursos al sistema disminuyendo las listas de espera, además de aportar una relación coste-efectividad favorable, puesto que permite llevar a cabo diagnósticos precoces; ofrece al paciente un servicio de mayor calidad, con lo que mejora la relación médico-paciente y consigue así una mayor satisfacción del enfermo ${ }^{3}$.

\section{ESTADO DE LA CUESTIÓN}

Efectivamente, la ecografía está cada vez más presente en nuestro entorno. Algunas sociedades científicas ya han apostado claramente por ella. En AP los pioneros fueron los médicos de la Sociedad Española de Médicos Generales y de Familia (SEMG), a través de su sección de ecografía. Posteriormente, la Sociedad Española de Médicos de AP (Semergen), a través de su grupo de trabajo en ecografía (GTE-Sermergen) y últimamente también la Sociedad Española de Medicina Familiar y Comunitaria (SEMFyC) 4 .

En Pediatría de AP no hay, todavía, una vía claramente definida e integral de organización que sirva de referente para el profesional interesado. La SEMG propició una Sección de Ecografía Pediátrica dentro de su escuela de ecografía, y GTE-Sermergen tiene su sección de Ecografía Pediátrica. Y es que son pocos los pediatras que asisten a los cursos de formación en ecografía... quizás porque están muy enfocados a medicina general, quizás por desconocimiento de las posibilidades de esta técnica aplicadas a la Pediatría de AP.

Gracias a una serie compañeros pediatras, la ecografía clínica pediátrica va tomando cuerpo pero, como vemos, utilizando infraestructuras de otras sociedades ajenas a las particularidades de la asistencia pediátrica en AP. Es aquí donde pensamos que hace falta un cambio de rumbo. La ecografía pediátrica debe retomarse desde la visión de los propios pediatras y desde las particularidades de la AP de salud.

En este sentido, y sensibles a esta cuestión, desde la Asociación Española de Pediatría de Atención Primaria (AEPap) se ha propiciado la creación de un grupo de trabajo, el Grupo de Ecografía Clínica Pediátrica, que pretende ser una referencia para el pediatra de AP que se quiera iniciar en esta técnica y que cubra el vacío existente antes descrito.

En esta línea, el Grupo de Ecografía Clínica Pediátrica de la AEPap está elaborando un documento de formación y acreditación de ecografía pediátrica dentro de la propia sociedad científica, lo que constituiría un hecho pionero en la historia de la ecografía pediátrica en AP.

\section{VENTAJAS E INCONVENIENTES DE LA ECOGRAFİA}

\section{Ventajas}

- Es una técnica diagnóstica de imagen no ionizante, inocua, sin efectos secundarios descritos, ni contraindicaciones conocidas.

- Es indolora y bien tolerada, lo que favorece la adhesión de nuestros pequeños pacientes.

- Permite controles repetidos, es manejable, dinámica, rápida y de accesibilidad inmediata.

- Es desplazable gracias a los equipos portátiles, lo que favorece llevar la técnica ecográfica a puntos muy distantes del centro de salud, lo que es muy importante en zonas con una dis- 
persión geográfica muy amplia, y también permite realizar ecografías a la cabecera del enfermo.

- Es reproducible, de tal manera que distintos exploradores encontrarán los mismos hallazgos.

- Económica, una vez hecha la inversión inicial del equipo y la formación de los profesionales.

- Permite emplear signos clínicos como la ecopalpación, por ejemplo en una colecistitis o una apendicitis.

- Ofrece una calidad de imagen para las partes blandas equiparable a la resonancia magnética y superior a la radiología simple.

- En la asistencia hospitalaria se usa como ayuda para hacer punción dirigida y permite el uso de contrastes ecográficos, lo que aumenta su poder diagnóstico evitando realizar pruebas donde se usen radiaciones ionizantes.

\section{Inconvenientes}

- El principal problema de la ecografía es que es operador-dependiente, es decir, su fiabilidad como técnica diagnóstica está estrechamente relacionada con la formación, experiencia y destreza del explorador.

- La presencia de gas y las superficies óseas impiden obtener imágenes de buena calidad imposibilitando, en ocasiones, la realización de la prueba diagnóstica.

\section{PATOLOGÍAS EN LAS OUUE PUEDE SERNOS DE UTILIDAD}

\section{Publicaciones, evidencias}

El número de publicaciones en las que se relacionan ecografía y AP va claramente en aumento en los últimos años. Sin embargo, si buscamos referencias en nuestro medio añadiendo el término "pediátrica" podremos comprobar la escasez de publicaciones.

Haciendo una lectura crítica, podremos comprobar que las publicaciones analizadas ${ }^{5-8}$ están basadas en ecografías realizadas en el medio hospitalario,
Tabla 1. Resumen del tipo de exploraciones

ecográficas pediátricas aplicables en AP según

las publicaciones consultadas ${ }^{5-8}$

- Exploración abdominal

- Exploración del sistema urinario

- Exploración cervical y de partes blandas

- Exploración del aparato locomotor/caderas

- Exploración del aparato genital femenino

- Exploración del aparato genital masculino

- Exploración craneal y del sistema nervioso central

incluso se contabilizan exploraciones como la transfontanelar, que está muy circunscrita al segundo nivel (Tabla 1). Una limitación importante sería disponer de sondas adecuadas para algunos de los estudios referidos cuando en los centros de salud habitualmente vamos a disponer como mucho de una sonda convex y una lineal.

Muchos de los estudios enumerados no llegarían a hacerse en AP, sobre todo los referidos a neonatos, pues la mayor parte de esas indicaciones, o bien están establecidas prenatalmente, o bien se establecen en las primeras horas de vida, con lo cual estas exploraciones suelen hacerse ya en el hospital antes de que el niño llegue al centro de salud. Lo mismo ocurre con aquellas patologías que, dadas sus características, consultan directamente en un Servicio de Urgencias, donde se le realiza la pertinente ecografía.

No obstante, se reconoce el valor de de estos resultados en el sentido de ser datos que nos pueden servir de utilidad para diseñar un listado de posibilidades diagnósticas en nuestro entorno y diseñar un proceso formativo dirigido.

\section{Experiencia propia}

Basada en las ecografías pediátricas realizadas con un equipo portátil (Sonosite micromaxx ${ }^{\circledR}$ ) con el que se cubren tres centros de salud de la zona Norte de Cáceres pertenecientes al Área de Salud de Plasencia, es decir, se trata de una Pediatría de Área. Por tanto estamos hablando de ecografías 


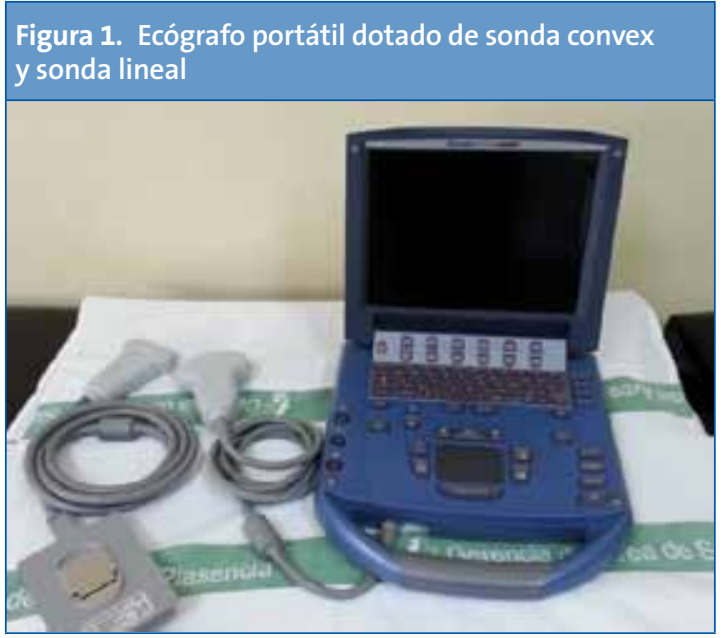

realizadas a niños en centros de salud y realizadas por su pediatra de AP.

Este equipo portátil está dotado con dos sondas: una sonda convex y una sonda lineal de $4,5 \mathrm{~cm}$ (Fig. 1). El hecho de usar un equipo portátil no solo valida la asistencia ecográfica en tres zonas de salud distintas, sino que además facilitaba su empleo en los cursos de ecografía organizados por instituciones y sociedades científicas en distintos puntos de la geografía extremeña.

No se pretende presentar aquí un estudio retrospectivo perfectamente estructurado desde el punto de vista estadístico, sino más bien presentar una casuística de las ecografías en niños que genera una consulta de Pediatría de AP que sirva de referencia a las posibilidades que tenemos los pediatras con esta técnica a nuestro alcance. De ello se puede inferir, también, las posibles necesidades formativas destinadas a los pediatras y según las particularidades de la AP.

A la hora de recoger los datos, el parámetro más relevante debería ser el motivo de consulta, con idea de saber qué es lo que nos lleva a los pediatras de AP a realizar una ecografía a uno de nuestros pacientes. Analizados los últimos siete años (20072013) y aunando motivos de consulta y hallazgos ecográficos, podemos agrupar las patologías en las que nos puede ser de utilidad según los siguientes ámbitos anatomoclínicos:
- Ecografía abdominal: el dolor abdominal (DA) en todas sus variantes (DA inespecífico, DA recurrente, DA agudo, etc.) es, con mucho, el motivo de la mayoría de la exploraciones abdominales. Alteraciones analíticas (función hepática). Dispepsia; estudio de estreñimiento.

- Ecografía urológica: infecciones de orina, enuresis, seguimiento de dilataciones pielocaliciales e hidronefrosis, alteraciones de la función renal, microhematurias, despistaje en niños con antecedentes familiares de poliquistosis renal.

- Ecografía inguinoescrotal: especialmente útil en Pediatría: asimetría testicular, dolor testicular, criptorquidia, quistes de epidídimo, hidroceles, quistes de cordón, hernia inguinoescrotal.

- Ecografía ginecológica: alteraciones menstruales, dismenorrea, hirsutismo.

- Ecografía del cuello: adenopatías, fibromatosis colli, parotiditis, quistes del conducto tirogloso. Tiene particular interés el estudio del tiroides: alteraciones analíticas, hipotiroidismo congénito, tiroiditis, nódulos.

- Ecografía musculoesquelética: despistaje de displasia y luxación de caderas en el lactante, sospecha de sinovitis de cadera, contusiones y bultomas, quistes de Baker.

- Ecografía de partes blandas: bultomas de cualquier localización, adenomegalias de cualquier localización, cuerpos extraños.

- Seguimiento de patologías ya diagnosticadas: esteatosis, quistes simples, la ya referida de dilataciones pielocaliciales e hidronefrosis, paciente monorreno.

- Screening: dentro de los protocolos de determinados síndromes, por ejemplo en el despistaje de tumores abdominales en un síndrome de Beckwith Wiedemann o el ya comentado de niños con antecedentes familiares de poliquistosis renal.

Este abanico de posibilidades puede variar en más o en menos en función de la formación, habilidad y experiencia del explorador, así como en función de las sondas y el software de que disponga el 
equipo ecográfico. Así, por ejemplo, la ecografía cardiaca pediátrica, con su sonda adecuada y la formación pertinente, sería una aplicación interesante para aquellos casos de soplos en lactantes fuera de la etapa neonatal precoz y en niños, lo que supondría un número importante de exploraciones que podríamos resolver en AP.

La casuística anteriormente expuesta coincide básicamente con los datos de los estudios publicados y aquí analizados. Esto es así porque la mayor parte de las ecografías que nosotros enviamos al segundo nivel son las que podrían tener resolución en AP, en nuestras manos, eso sí con la formación adecuada.

Cuando los hallazgos sugieren patología importante, estamos ante una situación en la que adelantamos el proceso diagnóstico y terapéutico, lo que puede suponer hablar de supervivencia del paciente, con todo lo que ello implica para el profesional y para la familia.

Pero se le da menos importancia a los hallazgos menores: en los cuadros clínicos como somatizaciones y trastornos funcionales con baja sospecha de patología orgánica se podría finalizar el proceso con una ecografía clínica realizada en el centro de salud ${ }^{9}$. Quiero dar valor aquí a todas esas exploraciones cuyos resultados hacen que el paciente no necesite ser derivado al segundo nivel; estos pacientes que se queda el pediatra y a los que puede seguir periódicamente con una ecografía clínica contribuyendo a evitar el colapso de los servicios de diagnóstico por la imagen.

\section{Dificultades encontradas}

- La presión asistencial: puede ser un obstáculo para aquellos pediatras con cupos muy amplios que no dejan huecos en la agenda para realizar otro tipo de actividades como la ecografía, la cual necesita su espacio y su tiempo, sobre todo al principio.

- La dotación del equipo ecográfico: el propio equipo ecográfico del centro de salud puede ser un obstáculo si no está dotado con las sondas apropiadas. La mayor parte de los ecógrafos de
AP suelen incluir una sonda lineal y una convex, lo que valdría para iniciarnos en la técnica. Incluso los equipos adscritos a los centros de orientación y planificación familiar, aunque disponen de sonda vaginal también suelen incluir una convex para estudio abdominal.

- Reticencias de otros profesionales: como los radiólogos, y reticencias de aquellos otros especialistas a los que son derivados los niños a resultas de los hallazgos ecográficos que nos encontremos.

- La formación inicial en cursos o talleres de más o menos tiempo de duración suele ser la suficiente para iniciarse. Pero en el transcurso de los días puede que demandemos otro tipo de exploraciones para las cuales no estamos preparados y para las que no encontramos manera de aprender. Aquí juega un papel importante ser autodidacta lo que, sin quitarle mérito al hecho en sí, hace que el aprendizaje sea más lento y probablemente insuficiente en algunas facetas.

\section{PROCESO FORMATIVO}

El momento idóneo de adquirir esta formación sería durante la residencia en Pediatría y sus Áreas Específicas. Así es en países como Alemania, donde al residente en Pediatría se le exige una capacitación en ecografía, al igual que se le exige en otras áreas. Hasta que esta formación se implante de forma reglada, una alternativa eficaz para la formación de pediatras de AP sería la realización de cursos específicos de iniciación y perfeccionamiento.

\section{Experiencias actuales}

Las sociedades científicas también tienen mucho que decir en la docencia. La pionera de todas ellas, la SEMG, organiza desde hace más de 20 años cursos de 100 horas que han sido un referente para muchos profesionales de la AP y el punto de partida para todos ellos.

Otros procesos formativos conocidos son el de la Comunidad de Madrid, en el que los cursos para sus médicos de AP son de 50 horas. 
Me he basado en la experiencia propia participando como docente en el "Programa de Implantación de la Ecografía en Atención Primaria en Extremadura". A través de este Programa se daba la formación inicial para médicos y pediatras de AP que cumplieran los criterios determinados en su momento para el fin del mismo. Así, se organizaron dos cursos al año, de 80 horas lectivas cada uno, dirigidos a un total de 30 médicos y pediatras de AP por cada curso. Se impartieron con continuidad desde el año 2008 hasta el año 2011, ambos inclusive.

Como podemos comprobar, no hay un modelo validado de docencia en ecografía para AP en España. En cualquier caso, un proceso formativo admisible pasaría por cursos teórico-prácticos desarrollados como de clases teóricas y prácticas en forma de talleres con modelos. Puede haber cursos cortos de iniciación de cuatro horas como los desarrollados en talleres en congresos y reuniones científicas, cursos monográficos, de perfeccionamiento... incluso una formación por niveles a semejanza de los realizados por Ginecólogos con la ecografía obstétrica.

\section{Las clases teóricas}

En la teoría debería explicarse con los medios audiovisuales disponibles:

- Los fundamentos físicos y técnicos básicos de la ecografía.

- Las imágenes elementales, los artefactos y su utilidad.

- La anatomía y la anatomía ecográfica normal del órgano o estructuras a estudiar.

- La relación de los posibles hallazgos ecográficos con la clínica.

- El lenguaje ecográfico apropiado y la realización del informe ecográfico ${ }^{6}$.

\section{Los talleres}

Deberían desarrollarse en grupos integrados por: cuatro o cinco alumnos, un docente, un ecógrafo y un modelo, y debería explicarse:
- El manejo del ecógrafo: identificar los botones de la consola de mandos. Seleccionar el tipo de sonda más adecuado para la exploración a realizar. Configurar los parámetros más adecuados y apropiados para cada órgano a estudiar.

- Situar la imagen en el monitor e interpretarla según los distintos planos de corte realizados con la sonda.

- Identificar las imágenes elementales y los artefactos.

- La sistemática de exploración para cada órgano o estructuras a estudiar.

- Realizar las mediciones de los órganos y de los posibles hallazgos ${ }^{6}$.

En un proyecto a largo plazo la ecografía abdominal debería centrar los esfuerzos en formación para luego complementar los conocimientos con cursos centrados en cuello, incluido el tiroides, y cadera del lactante y del niño.

\section{CONCLUSIONES}

El pediatra de AP no puede estar ajeno a la tendencia actual de interés por la ecografía, teniendo en cuenta el potencial diagnóstico de la técnica y lo que nos puede aportar en nuestro quehacer habitual.

La ecografía es una técnica diagnóstica que reúne una serie de ventajas que la hacen idónea para el paciente pediátrico; entre ellas destacan su inocuidad y la ausencia de efectos secundarios, y también que no es dolorosa. A todo ello se une que el paciente pediátrico es el ideal por su proporción de grasa en el cuerpo, obteniendo, por lo general, imágenes de mejor resolución que en el adulto.

La ecografía en manos del pediatra de AP constituye, junto con la clínica y la exploración, una forma de aumentar el rendimiento diagnóstico que contribuye a redirigir mejor al paciente, con lo que aumenta la capacidad resolutiva del profesional.

Unido a todas las anteriores ventajas, se suman las siguientes: es inocua, indolora, repetible, manejable, dinámica, rápida y de accesibilidad inmediata. 
Es desplazable, es reproducible, y económica.

No debemos olvidar que el principal inconveniente es que es explorador-dependiente, por lo que se precisa una buena formación y una experiencia cuanto más extensa mejor para sacarle el mayor rendimiento y aumentar así su fiabilidad.

La lista de motivos de consulta o patologías en las que nos puede ser útil a los pediatras de AP es muy amplia, dependiendo de la dotación de los equipos que dispongamos en nuestro centro de salud y de nuestra formación, experiencia y habilidad, pero básicamente pasa por: estudio ecográfico abdominal en todas sus vertientes, estudio nefrourológico, estudio ginecológico, estudio de la patología inguinoescrotal, estudio del cuello y el tiroides, exploraciones musculoesqueléticas, estudio de partes blandas, seguimiento de patologías ya diagnosticadas y método de screening.

Una buena formación en ecografía abdominal preferentemente y luego en cuello-tiroides y en cade-

\section{BIBLIOGRAFÍA}

1. Díaz Rodríguez N. La ecografía en atención primaria. SEMERGEN. 2002;28:376-84.

2. Grupo de ecografía de Atención Primaria de Extremadura. Ecografía para Atención Primaria. Guía clínica. Badajoz: Junta de Extremadura; 2010.

3. Salcedo Joven I, Segura Grau A, Herzog Verrey R, Fernández Rodríguez T, Joleini Joleini S, Valero López I. Evaluación de la actividad ecográfica de un profesional de atención primaria durante un periodo de siete meses. Euro Eco. 2012;3:95-8.

4. Vicente-Molinero A, Aznar-Cantín S, Yáñez-Rodríguez F. Ecografía en Atención Primaria: estado de la cuestión. SEMERGEN. 2009;35:58-61.

5. Ceres Ruiz L, Bravo Bravo C. Uso racional de las pruebas diagnósticas. Ecografía en Pediatría de Atención Primaria. Form Act Pediatr Aten Prim. 2010;3:229-37. ra capacitarían a un pediatra de AP de forma adecuada para atender solventemente la mayoría de la patología de su quehacer habitual. Esta formación debería darse en forma de cursos teóricopráctico (talleres) con una serie de requisitos mínimos para iniciarse en la técnica.

\section{CONFLICTO DE INTERESES}

El autor declara no presentar conflictos de intereses en relación con la preparación y publicación de este artículo.

\section{ABREVIATURAS}

AEPap: Asociación Española de Pediatría de Atención Primaria • AP: Atención Primaria • DA: dolor abdominal • GTESermergen: grupo de trabajo en ecografía de Semergen - Semergen: Sociedad Española de Médicos de AP • SEMFyC: Sociedad Española de Medicina Familiar y Comunitaria - SEMG: Sociedad Española de Médicos Generales y de Familia • US: ultrasonido.

6. Gil Sierra A, Méndez Alonso MA, Gutiérrez Pantoja A. Ecografía: herramienta útil para todos. En AEPap ed. Curso de Actualización Pediatría 2014. Madrid: Exlibris Ediciones; 2014. p. 507-10.

7. García Palomeque JC, Ceballos Aragón JM. Aplicación de la ecografía pediátrica en Atención Primaria; interconexión con la atención hospitalaria. Rev Pediatr Aten Primaria. 2011;13:359-66.

8. Osiniri Kippes I. ¿Qué puede hacer el pediatra de Atención Primaria con el ecógrafo? XXVII Congreso Nacional de la Sociedad Española de Pediatría Extrahospitalaria y Atención Primaria. Pediatr Integral. 2013.

9. Alonso Roca R, Díaz Sánchez S. Utilización de la ecografía en atención primaria [en línea]. Disponible en: www.somamfyc.com/Grupos/Ecografias/Documen tos.aspx 